\title{
AN INTEGRATED APPROACH TO SEISMIC EVENT LOCATION: \\ I. EVALUATING HOW METHOD OF LOCATION AFFECTS THE VOLUME OF GROUPS OF HYPOCENTERS
}

Cliff Frohlich

Institute for Geophysics

University of Texas at Austin

8701 North Mopac

Austin, Texas 78759

12 November 1992

Scientific Report No. 1

Approved for public release; distribution unlimited

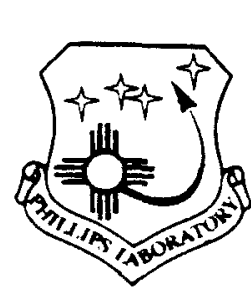

PHILLIPS LABORATORY

Directorate of Geophysics

AIR FORCE MATERIEL COMMAND

HANSCOM AIR FORCE BASE, MA 01731-5000 


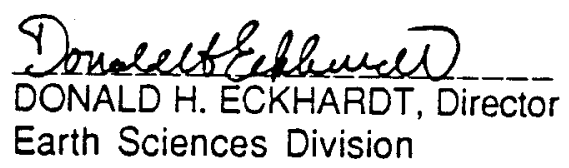

This document has been reviewed by the ESC Public Affairs Office (PA) and is releasable to the National Technical Information Service (NTIS).

Qualified Requestors may obtain additional copies from the Defense Technical Information Center. All others should apply to the National Technical Information Service.

If your address has changed, or if you wish to be removed from the mailing list, or if the addressee is no longer employed by your organization, please notify PL/TSI, Hanscom AFB, MA 01731-5000. This will assist us in maintaining a current mailing list.

Do not return copies of this report unless contractual obligations or

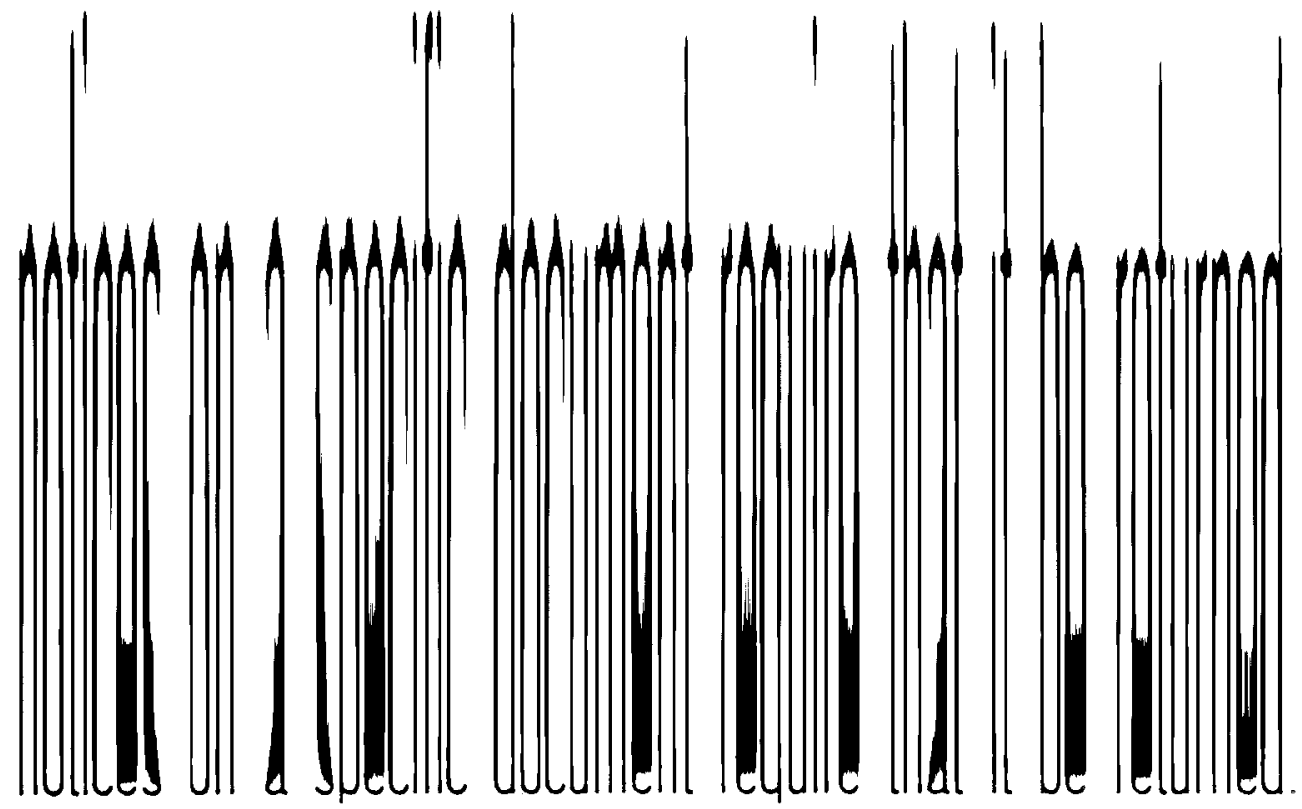


Public reooring burcen for this collection of information is estimated to average 1 hour per response, inciuding the time for reviewing instructions. searching existing data sources, athering and mantaining the data needed, and completing and reviewing the collection of information. Send comments regarding this burden estima te or any other aspect of this gailerion at intormation including suggestions for reducing this Durden, to Washington Headauarters Services. Directorate tor intormation Operations and Redorts. 1215 Jefterson Davis Highway, Suite 1204, Artington. VA 22202-4302. and to the Office of Management and Budget, Paperwork Reduction Project (0704-0 188), Washington. DC 20503.

\begin{tabular}{|l|l|l} 
1. AGENCY USE ONLY (Leave blank) & $\begin{array}{l}\text { 2. REPORT DATE } \\
\text { November 12, 1992 }\end{array}$ & $\begin{array}{l}\text { 3. REPORT TYPE AND DATES COVERED } \\
\text { Scientific Report \# } 1\end{array}$ \\
\hline
\end{tabular}

\section{TITLE AND SUBTITLE}

5. FUNDING NUMBERS

An Integrated Approach to Seismic Event Location:

I. Evaluating How Method of Location Affects the Volume of Groups of Hypocenters

\section{AUTHOR(S)}

Clifford A. Frohlich

\section{PERFORMING ORGANIZATION NAME(S) AND ADDRESS(ES)}

Institute for Geophysics

University of Texas at Austin

8701 North Mopac Expressway

Austin, TX 78759-8397

\section{SPONSORING/MONITORING AGENCY NAME(S) AND ADDRESS(ES)}

Phillips Laboratory

Hanscom AFB, MA 01731-5000

Contract Manager: Katharine Kadinsky-Cade/GPEH
PE $61102 \mathrm{~F}$
PR 2309
TA G2

WU AZ

Contract:

F19628-91-K-0026

8. PERFORMING ORGANIZATION REPORT NUMBER
10. SPONSORING/MONITORING AGENCY REPORT NUMBER

PL-TR-92-2323

11. SUPPLEMENTARY NOTES

12a. DISTRIBUTION/AVAILABILITY STATEMENT

Approved for public release, distribution unlimited

13. ABSTRACT (Maximum 200 words)

When seismic events occur in spatially compact clusters, the volume and geometric characteristics of these clusters often provides information about the relative effectiveness of different location methods, or about physical processes occurring within the hypocentral region. This report defines and explains how to determine the convex polyhedron of minimum volume (CPMV) surrounding a set of points. We evaluate both single-event and joint hypocenter determination (JHD) relocations for three rather different clusters of seismic events; 1 ) nuclear explosions from Mururoa relocated using $\mathrm{P}$ and $\mathrm{PKP}$ phases reported by the ISC; 2 ) intermediate depth earthquakes near Bucaramanga, Colombia, relocated using $\mathrm{P}$ and $\mathrm{PKP}$ phases reported by the ISC; and 3) shallow earthquakes near Vanuatu (formerly, the New Hebrides), relocated using $P$ and $S$ phases from a local station network. This analysis demonstrates that different location methods markedly affect the volume of the CPMV, however, volumes for $\mathrm{JHD}$ relations are not always smaller than volumes for single-event relocations.

\begin{tabular}{|c|c|}
\hline $\begin{array}{l}\text { 4. SUBJECT TERMS } \\
\text { Seismic event locat }\end{array}$ & on, seismic strain, \\
\hline $\begin{array}{l}\text { 17. SECURITY CLASSIFICATION } \\
\text { OF REPORT } \\
\text { Unclassified }\end{array}$ & $\begin{array}{l}\text { 18. SECURITY CLASSIFICATION } \\
\text { OF THIS PAGE } \\
\text { Unclassifled }\end{array}$ \\
\hline
\end{tabular}

NSN 7540-01.280-5500
15. NUMBER OF PAGES

34

16. PRICE CODE

20. LIMITATION OF ABSTRACT

SAR 19. SECURITY CLASSIFICATION
OF ABSTRACT

Unclassified 


$\cdot \quad \cdot \quad \cdot$




\section{TABLE OF CONTENTS}

1. Introduction ...................................................................

2. Methods and Test Data............................................................... 5

A. Convenient Software for Joint Hypocentral Determination................... 5

• Minimal Editing ........................................................ 5

- Choice of Phase and Weight .......................................... 7

- Variable Association....................................................... 7

- Method of Solution ................................................... 7

- Error Analysis Options........................................................ 7

B. Determining the Minimum-Volume Convex Polyhedron ..................... 8 Enclosing a set of Points in Space

• Background ........................................................... 8

• Algorithm..................................................................... 9

- Statistics: Bounding Volume, Surface Area, Shape Factor ................. 14

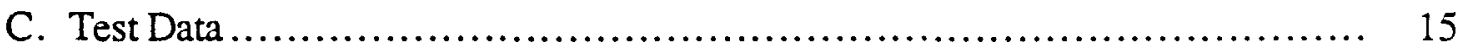

- Earthquakes in the Bucaramanga Nest .............................. 15

- Nuclear Explosions from Mururoa Recorded Teleseismically............... 17

- Earthquakes Recorded by Ocean Bottom Seismographs in Vanuatu .......... 20

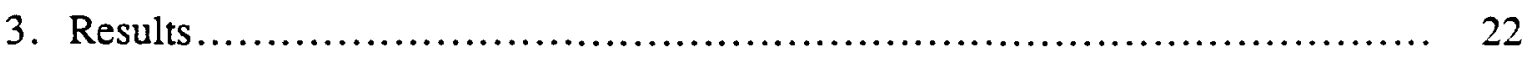

A. Earthquakes in the Bucaramanga Nest ................................. 22

B. Nuclear Explosions from Mururoa Recorded Teleseismically..................... 24

C. Earthquakes Recorded by Ocean Bottom Seismographs in Vanuatu ............ 24

4. Discussion and Conclusions ..................................................... 26

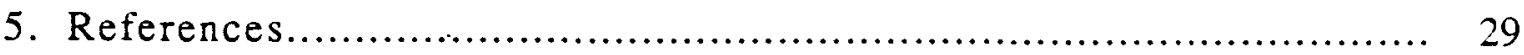





\section{INTRODUCTION}

There are numerous applications where the objectives are to obtain precise relative locations of seismic sources, and to evaluate the accuracy and precision of these locations. Research in three different areas during the past 15 years which has focused on meeting these objectives includes:

1) Improvements in instrumentation and data acquisition. Today most seismic data are recorded in digital form, and there exist more broad-band seismic stations than previously.

2) Methods for joint hypocenter determination (JHD). Because earth structure may be inhomogeneous or poorly known, it may be useful to adjust travel times by applying station corrections. Since Douglas (1967) and Dewey (1972) noted that there were often advantages in solving for hypocenters and for these station corrections simultaneously, several investigators have suggested more efficient schemes for finding these parameters without performing a brute-force iterative inversion (Frohlich, 1979; Jordan and Sverdrup, 1981; Hermann et al., 1981; Pavlis and Booker, 1983; Pavlis and Hokanson, 1985; and Pujol, 1988).

3) Methods for evaluating errors in event locations. The classical approach to error analysis utilizes a formal statistical analysis relying on underlying assumptions concerning the distribution of errors (e. g., Flinn, 1965; Jordan and Sverdrup, 1981; Boyd and Snoke, 1984). More recent research has emphasized the importance of systematic errors (e. g., McLaren and Frohlich, 1985; Pavlis, 1992), and considered ways to estimate errors possessing unknown or unusual distributions (Tichelaar and Ruff, 1989).

The present report discusses our preliminary efforts to evaluate how different event location methods interact with various types of phase arrival data. For this evaluation process we have developed a modular and convenient JHD software package which we have applied to three sets of clustered event data (Figure 1), each with quite different properties. These data sets are (Table 1);1) 29 nuclear explosions from Mururoa, located using teleseismic $P$ and PKP phases from stations in a restricted azimuthal range; 2) 41 intermediate focus earthquakes from the nest near Bucaramanga, Colombia, located using teleseismic $P$ phases from stations in a broad azimuthal range; and 3) 46 shallow 


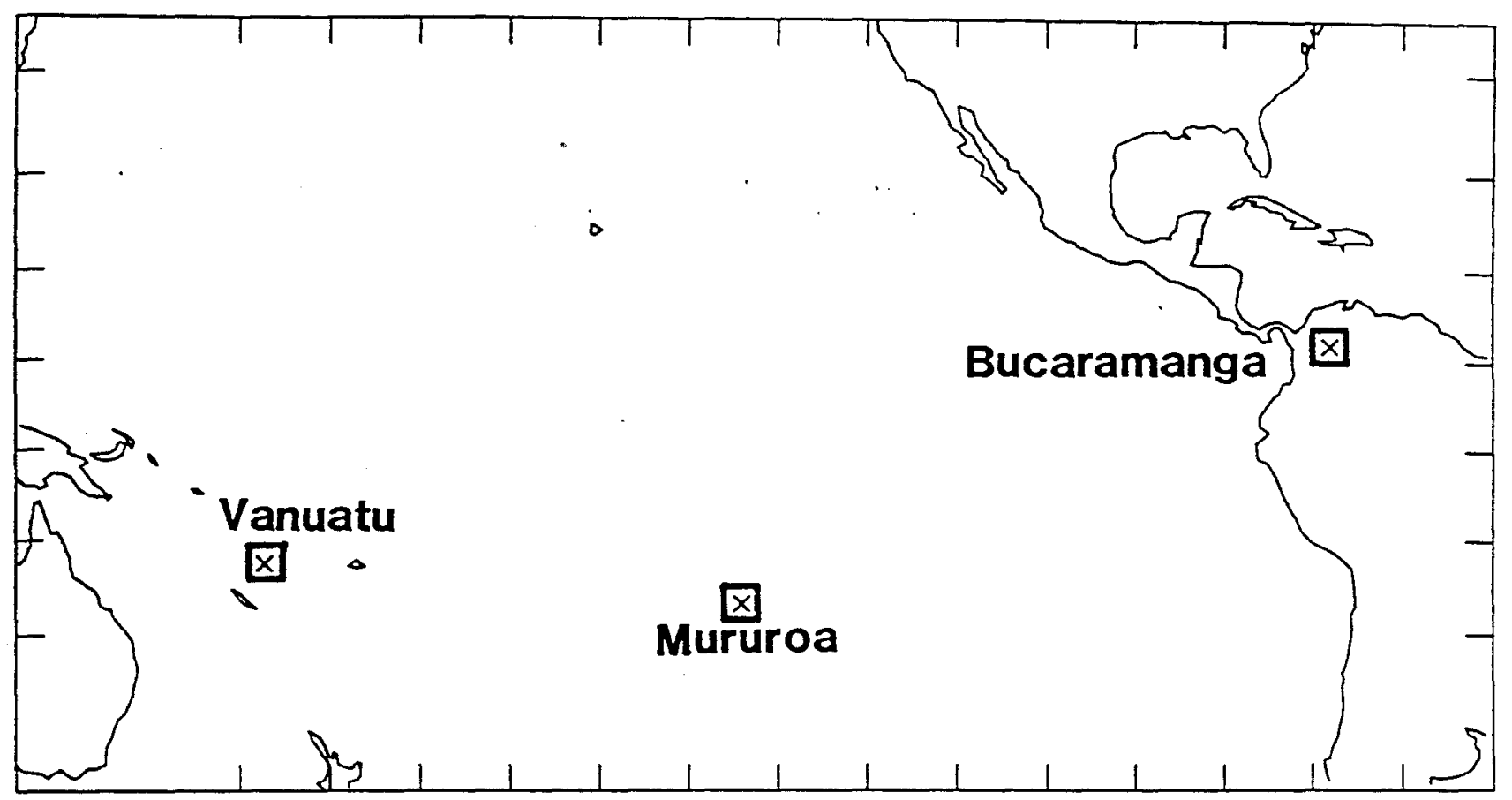

Figure 1. Location of Bucaramanga, Mururoa and Vanuatu study areas. In this report we evaluate the performance of the preliminary version of a seismic event relocation program using localized clusters of events occurring in each of these areas. 
Table 1: Comparative Characteristics of Three Hypocentral Groups

\begin{tabular}{llllll}
\hline Geographic Region & Focal Depth & Phase Data Type & Phases & Azimuthal Gap & Data Source \\
\hline Bucaramanga & Intermediate $(\sim 160 \mathrm{~km})$ & $\begin{array}{l}\text { Teleseismic, } \\
\text { Regional }\end{array}$ & P, PKP & $<110$ & ISC \\
Mururoa & Surface $(\sim 1 \mathrm{~km})$ & Teleseismic & P, PKP & $<160$ & ISC \\
Vanuatu & Shallow $(\sim 30 \mathrm{~km})$ & Local & P, S & $<240$ & Field Observations \\
\hline
\end{tabular}


earthquakes from a concentration east of Efate, Vanuatu, located using $\mathrm{P}$ and $\mathrm{S}$ phases from a local network and a network of ocean bottom seismograph stations.

For the JHD software package, the mathematical approach towards solving for hypocenters, determining station corrections, and evaluating errors is not new. Rather, the design focus for this program is to achieve a flexible framework, where it is.relatively. simple to add a variety of different modules for varying location method, travel time calculation, and error analysis. The program strives to achieve easy manipulation of phase arrival input data. It includes a simple method for assigning the same station correction to different stations or to different station/phase combinations. There are a variety of display options for output, and it is straightforward to use output data as input for a succeeding program run. By changing only a few input parameters we use this software package for locating local, regional or teleseismic events. Because the design is modular, it is straightforward to replace or modify the routines which calculate phase arrival times, solve the JHD equations, estimate errors, etc. We expect that a preliminary version of this software will be available for distribution sometime in 1993.

This report also presents a method for determining the minimum-volume convex polyhedron enclosing a set of points in space. When event hypocenters are thought to originate from a point in space, the volume of this polyhedron can provide a measure of the precision of event location. Where event hypocenters occupy a non-zero volume, knowledge of the shape and volume of this polyhedron provides a means for comparing seismic moment rates to models of strain release and material deformation. We have also applied this method to simulate crystallization in metamorphic rocks (e.g., Carlson and Denison, 1992). Here, the approach is to simulate a rock with exactly the same bounding convex polyhedron as the crystallization centers in a real rock, thus insuring that edge effects influence statistical tests in the same way for both the real and simulated rock. To the best of our knowledge, the idea of using a minimum volume polyhedron as a practical enclosure for a set of points has not been suggested previously in the seismological or geological literature. 


\section{METHODS AND TEST DATA}

\section{A. Convenient Software for Joint Hypocentral Determination}

Concerning the determination of locations for seismic events - each situation is different, and yet every situation is the same. Concerning differences: the available data may be phases from teleseismic stations, or phases recorded at a local network; there may be $\mathrm{P}$ phases only, or P, S, PKP, and a host of more exotic phases; there may be thousands of seismic events of variable data quality; or a handful of well-recorded events; either single-event or JHD locations may be desired. Concerning similarities: in each case much of the research effort involves editing input data till it is in a convenient format for location software; then, evaluating the robustness of locations by varying data weights, station combinations, location methords, and error analysis schemes. Recently, larger and more diverse data sets have become available at data management centers, thus it has become desirable to possess a single unified software package which can be applied to all these data types and location problems.

Thus, recently we have begun to develop a software package that is appropriate for a broad variety of data types and location problems (see Table 2). This section describes some of the characteristics of the preliminary version of this software.

Minimal Editing: The program requires separate input files for trial hypocenters, observed phase arrivals, station-phase variable assignation, and setting defaults. Each trial hypocenter must have an identification number, used to associate hypocenters with phases in the phase arrival file and used in the program throughout the calculations. To choose a collection of events for location, the user need only specify the identification numbers of the desired events in the defaults file. Thus, to locate different combinations of events, the user does not have to edit the trial hypocenter file or the phase arrival file.

In all input files, the program ignores comment lines beginning with the letter " $\mathrm{c}$ ". Thus, in the phase arrival file the user can insert comments explaining additions, alterations, or excisions of phase arrivals. Or, in the hypocenter file the user can use comments to retain a running record of event locations obtained using different default values for the program. 


\section{Table 2: Characteristics of the Preliminary Relocation Program}

1. Input files
A. Defaults
B. Trial hypocenters
C. Station-phase associations - description of which station-phase combination will be used during relocation, and designation of station-phase combinations which will share the same station correction for JHD relocation.
D. Phase arrival times
E. Station locations

2. Output files
A. Summary - defaults, locations on all iterations, large residuals, table of azimuths of phase arrivals, table of all residuals
B. Final hypocenters - in file with same format as 1.B
C. Final station-phase associations and station corrections - in same format as 1.C
D. Phase arrival times - same format and information as 1.D except output includes distance, azimuth, and residual information
E. Event by Event Summary - one page for each event with input data, weights, distance, azimuths, residuals, location, error ellipsoid, etc.

3. Travel time options
A. Flat earth model times - determined by program written by the author and described by Frohlich et al. (1982)
B. J-B P times - determined from a Table.
C. IASPEI 1991 travel times - determined from a program written by Ray Buland and described by Kennett (1991).

4. Phase weighting options

A. Equal weights for all data

B. User-assigned weights depending on user-assigned quality - For example, user assigns each phase a quality $1,2,3$, or 4 and then specifies that these shoud receive weights $1.0,0.5,0.25$, and 0 . respectively.

C. Residual-dependent boxcar/ramp - For user-selected constants B and R, weights are 1.0 for residuals between $-B$ and $+B$, and vary linearly between 0.0 and 1.0 for residuals between $-B-R$ and $-B$, and between $B$ and $B+R$.

D. Residual-dependent Gaussian weights - For user-selected constant $G$, weights are $\exp \left(-(\operatorname{Res} / G)^{2}\right)$.

E. Azimuthal weights - The weights are normalized so that the weights are equal for each of $\mathrm{N}_{\mathrm{az}}$ user-specified azimuthal sectors. The user must specify the azimuth of the boundary between the first and second azimuthal sector.

F. Combinations or weights - The user can specify that the weights used for relocation are the product of the weights determined from any or all of the methods A-E above. 
Choice of Phase and Weight: In the default file the user can choose to determine phase arrivals using several different options. The presently available options include: flat earth $\mathrm{P}$ or $\mathrm{S}$ times calculated for a user-specified structure (Frohlich et al., 1982), $\mathrm{P}$ times interpolated from the J-B tables, or any of the phases including P, S, PcP, ScP, PKP, etc. calculated from the IASPEI 1991 software (Kennett, 1991).

The user can also specify a variety of phase weighting schemes to influence how travel time residuals affect the least squares location process. The present options include: phase residuals weighted equally; phase residuals weighted depending on a user assigned phase quality, with the quality-dependent weights set by the user; phase residuals weighted depending on a boxcar-ramp function, with the width of the boxcar and ramp set by the user; and phase residuals weighted depending on a Gaussian function, with the width of the Gaussian set by the user. The user can also choose to implement an azimuthal weighting scheme, so that the least squares process weights equally arrivals from each of a user-selected number of azimuthal sectors. Finally, the user can select more than one of these weighting options, for example, one can choose to equalize weights azimuthally, with the weights being dependent on a Gaussian, but adjusted for the user assigned phase quality.

Variable Association: In the station-phase variable assocation file, the user can choose to calculate and apply the same station correction at several different stations. Thus, for $\mathrm{JHD}$ relocations one can apply the same station correction variable for stations in similar tectonic provinces. Or, the user can choose to have station corrections for different phases be the same except for a specified multiplicative factor. Thus, if desired one can use the same station correction for $\mathrm{P}$ and $\mathrm{S}$ phases at a particular station; or, one could have the $\mathrm{S}$ station correction be, say, 1.71 times the $\mathrm{P}$ station correction.

Method of Solution: Currently, for either fixed or variable focal depths the user can choose single-event locations; or relocation by the "fast" JHD method described by Frohlich (1979). The future plan is also to include options for the relocation method described by Herrmann (1981), and to use singular-value decomposition to solve the JHD equations as suggested by Jordan and Sverdrup (1981).

Error Analysis Options: Currently we calculate error ellipsoids for all hypocenters using a classical approach (Flinn, 1965; Willemann and Frohlich, 1987). Future plans include the option to use projection operators as suggested by Jordan and Sverdrup (1981). 
Also, to investigate the importance of data from individual stations, we hope to develop a "mini-jackknifing" option which determines how much each location is affected by removing data from individual stations or station groups.

\section{B. Determining the Minimum-Volume Convex Polyhedron Enclosing a Set of Points in Space}

Background: There exist numerous applications in seismology and geology where it is useful to define a volume in space which encloses a set of points. For example:

1. For groups of earthquakes or explosions which are thought to originate from the same location, this volume will be a measure of the uncertainty in location.

2. For groups of earthquakes or explosions thought to originate from a region having non-zero volume, the defined volume is a measure of the degree of localization of the events. It also provides a way of estimating moment release, since there is a simple relationship between seismic moment, volume, and seismically released strain (e. g., see Kostrov, 1974, or Frohlich and Apperson, 1992).

3. Whenever it is desirable to simulate spatial processes so as to make statistical comparisons with real data, one requires a defined volume which has comparable statistical properties to the real data. For example, we might desire that the "shape" of the defined volume be such that statistical tests would suffer from the same edge effects, due to the finite size of the volume, as do the real data.

It is possible to propose a variety of different volumes which enclose a set of points. For example, in any coordinate system one can determine a rectangular prism enclosing a set of points simply by searching to find the minimum and maximum value of each of the coordinates in the set. If one desires a volume which is coordinate-systemindependent, one could attempt to find the sphere of minimum volume which encloses the points. However, neither of these volumes is likely to provide a satisfactory description of the region occupied by the points unless there is reason to expect that this region is rectangular, or spherical.

A more appropriate choice is the convex polyhedron of minimum volume enclosing the set of points. This is unique and will have approximately the same "shape" as the set of 
points. Since it may not be immediately obvious how to determine this polyhedron, below we describe an algorithm to accomplish this. Upon request, the author of this report will provide a Fortran program implementing this algorithm. This program has been applied to determine the minimum volume convex polyhedron enclosing as many as 4755 points (Figure 2).

Algorithm: The basic approach of the algorithm below rests on the fact that any three distinct points $\mathrm{i}, \mathrm{j}, \mathrm{k}$ in a set $\mathrm{S}$ of $\mathrm{N}$ points will define one of the triangles forming the convex polyhedron bounding $S$ if all of the points in $S$ besides $i, j$, and $k$ lie within or on the same side of the plane defined by $\mathrm{i}, \mathrm{j}$, and $\mathrm{k}$ (Figure 3 ). Thus, in principle, one could determine all the faces of the bounding polyhedron simply by searching through all possible combinations of three points in S. Unfortunately, if $\mathrm{N}$ is large this is not feasible, since the number of possible combinations goes as $\mathrm{N}^{3}$.

However, we can significantly reduce the search if we reorder the $\mathrm{N}$ points in terms of one of the vertical coordinates and then search for faces beginning with the bottommost points and proceding upward (Figure 4). We first find all the triangular faces meeting at the bottommost point (call it point $b$ ). We next proceed to the bottommost remaining point (call it point a) along the upper edge of the surface determined by these faces (the "edge polygon"), and search for additional faces utilizing this point. Because the faces already found entirely surround all points in S below point a, we need only search the array $\mathrm{R}$ for possible faces among points situated above point a. After each triangular face is found, we check the points along the edge polygon to see if connecting any two of them will give us another face, as well as reduce the complexity of the edge polygon. Then, we repeat the process of finding faces connected to the bottommost remaining point along the edge polygon, until we have found all the faces enclosing the set $\mathrm{S}$.

To visualize this algorithm, it is convenient to think of how you might use triangular tiles to construct a vase to hold water. A natural approach might be to first join together the tiles meeting at the lowermost portion of the vase till they formed a shallow basin. If this basin were filled with water till it overflowed, you would then progressively add tiles at the point of overflow, building up the vase from bottom to top till the vase was enclosed completely. At each step of construction you could safely ignore interior points below the point of overflow, because they cannot be part of the exterior of a convex polyhedral vase. 
TOP:VIEW TOP SURFACE

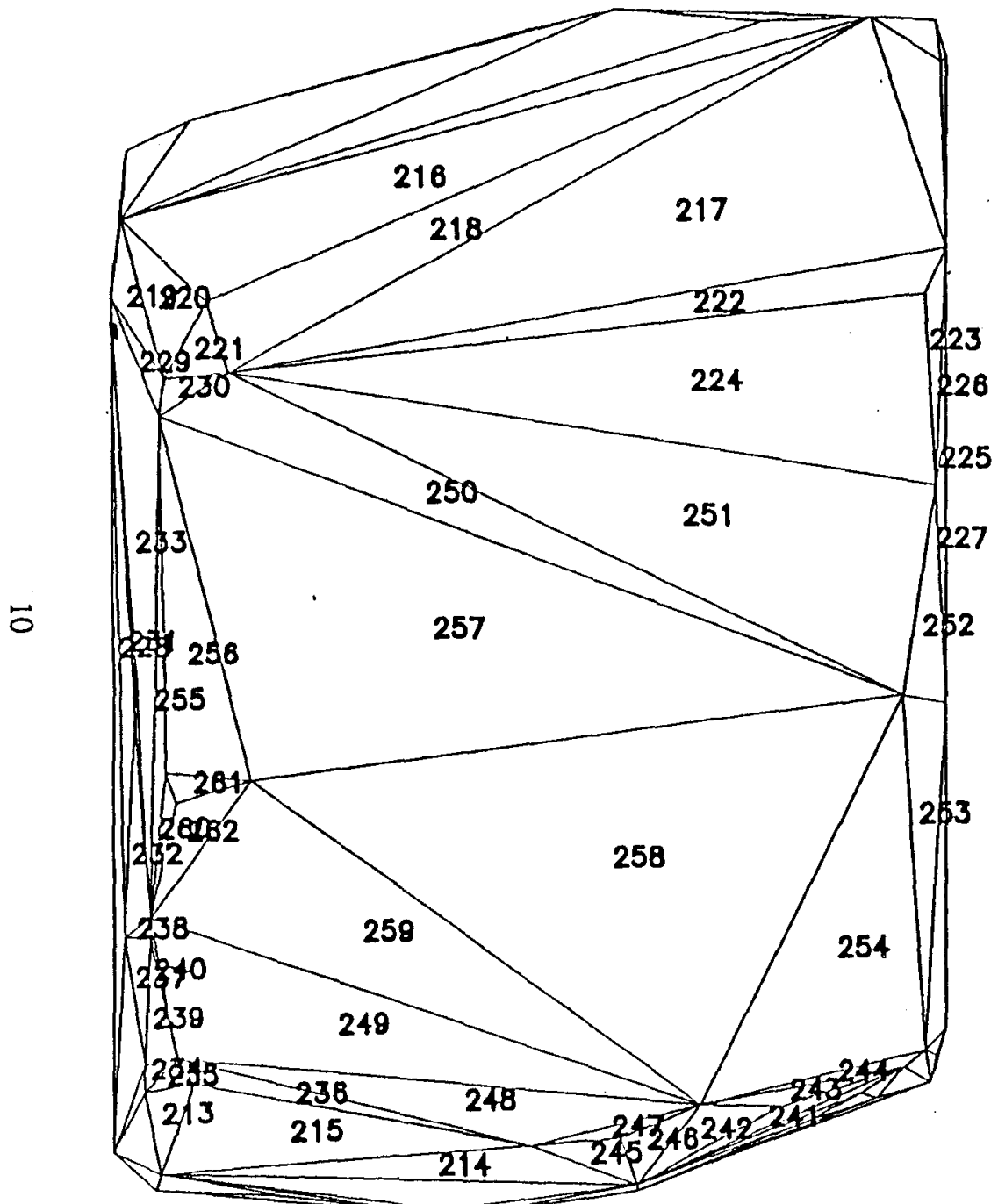

TOP VIEW BOTTOM SURFACE

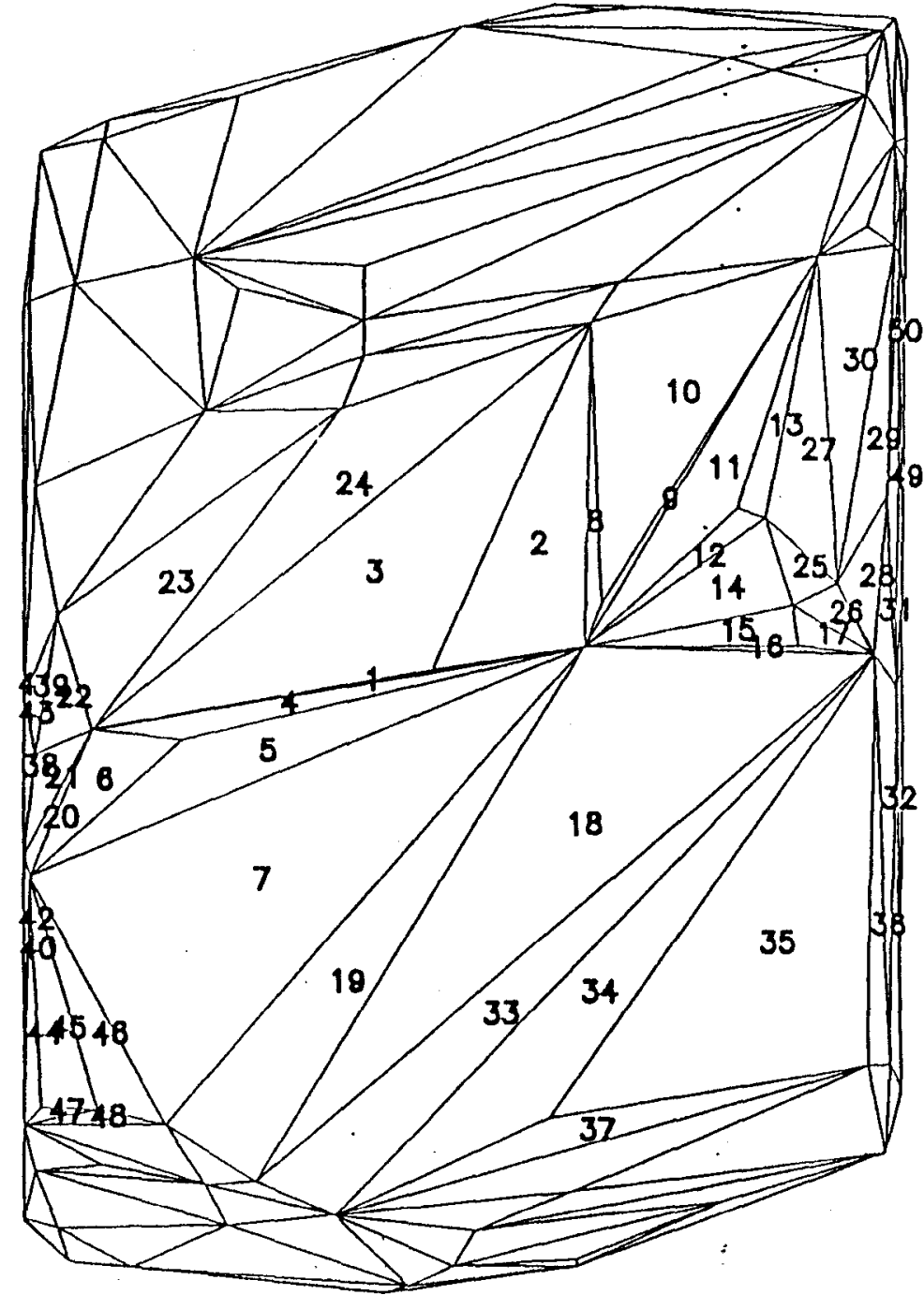

Figure 2. Minimum-volume convex polyhedron enclosing 4755 points which are porphyroblast crystallization centers for a rock sample described by Carlson and Denison (1992). Each triangle represents three points on the exterior of the bounding polyhedron. The left and right figures depict bounding face triangles as viewed from above the sample, with the left figure depicting the faces on the top surface of the sample, and the right figure depicting faces on the bottom surface of the sample. For this sample, the bounding polyhedron consisted of 133 points connected by 393 edges, making up 262 faces. Thus, 4622 of the 4755 points were on the interior of the bounding polyhedron. The numbers in each triangle tell the order in which the programmed algorithm found the first 50 and the last 50 bounding faces. 

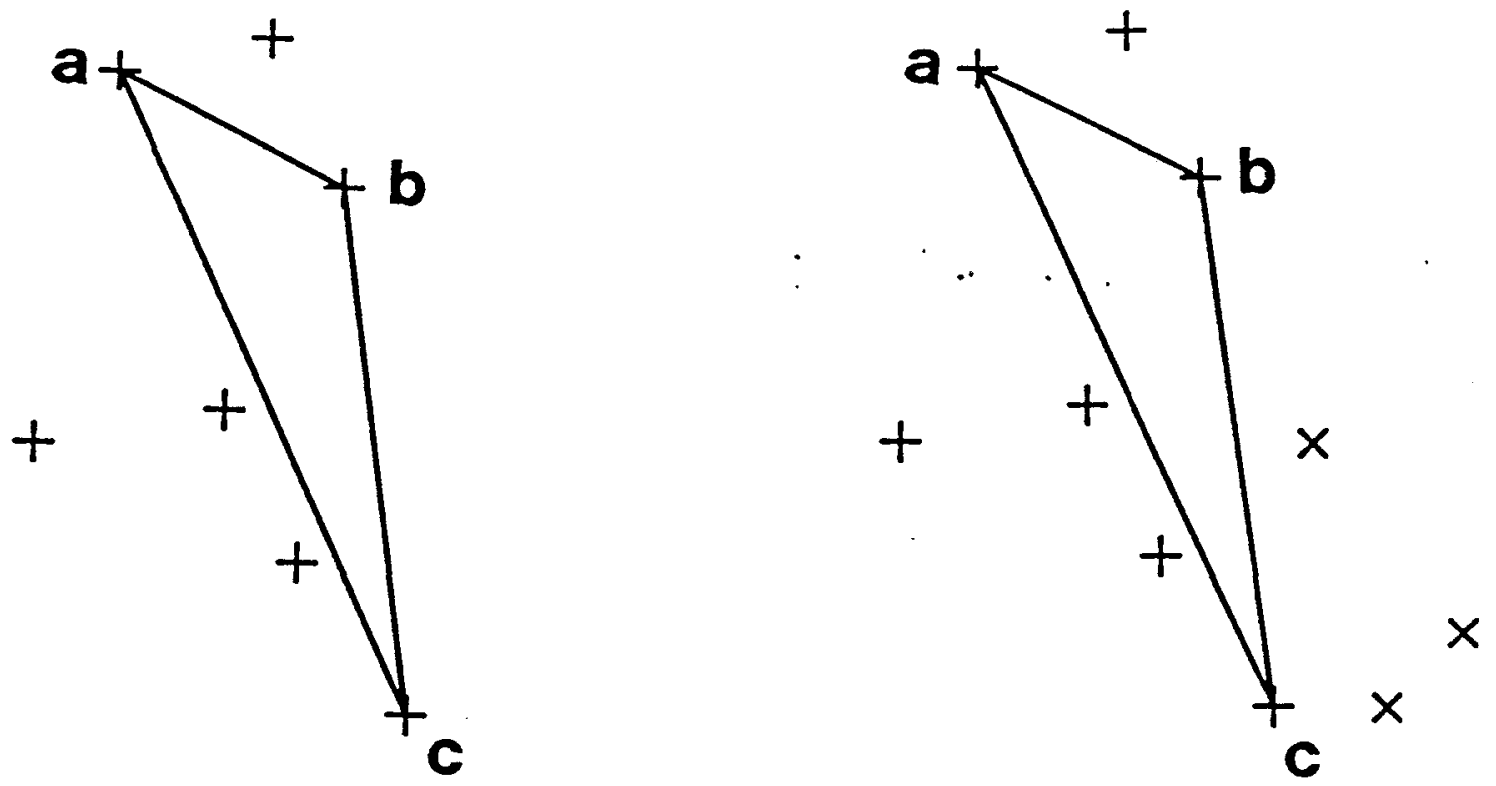

Figure 3. A plane $P$ containing three points $a, b$, and $c$ in a set $S$ will be part of the mininum-volume convex bounding polyhedron if and only if all the remaining points in $S$ lie within or on one side of $\mathrm{P}$ (left diagram). If there are points on both sides of the plane (right diagram), it cannot be part of the bounding polyhedron. In these diagrams, points on one side are represented by + symbols, points on the other side by $\mathrm{X}$ symbols. 


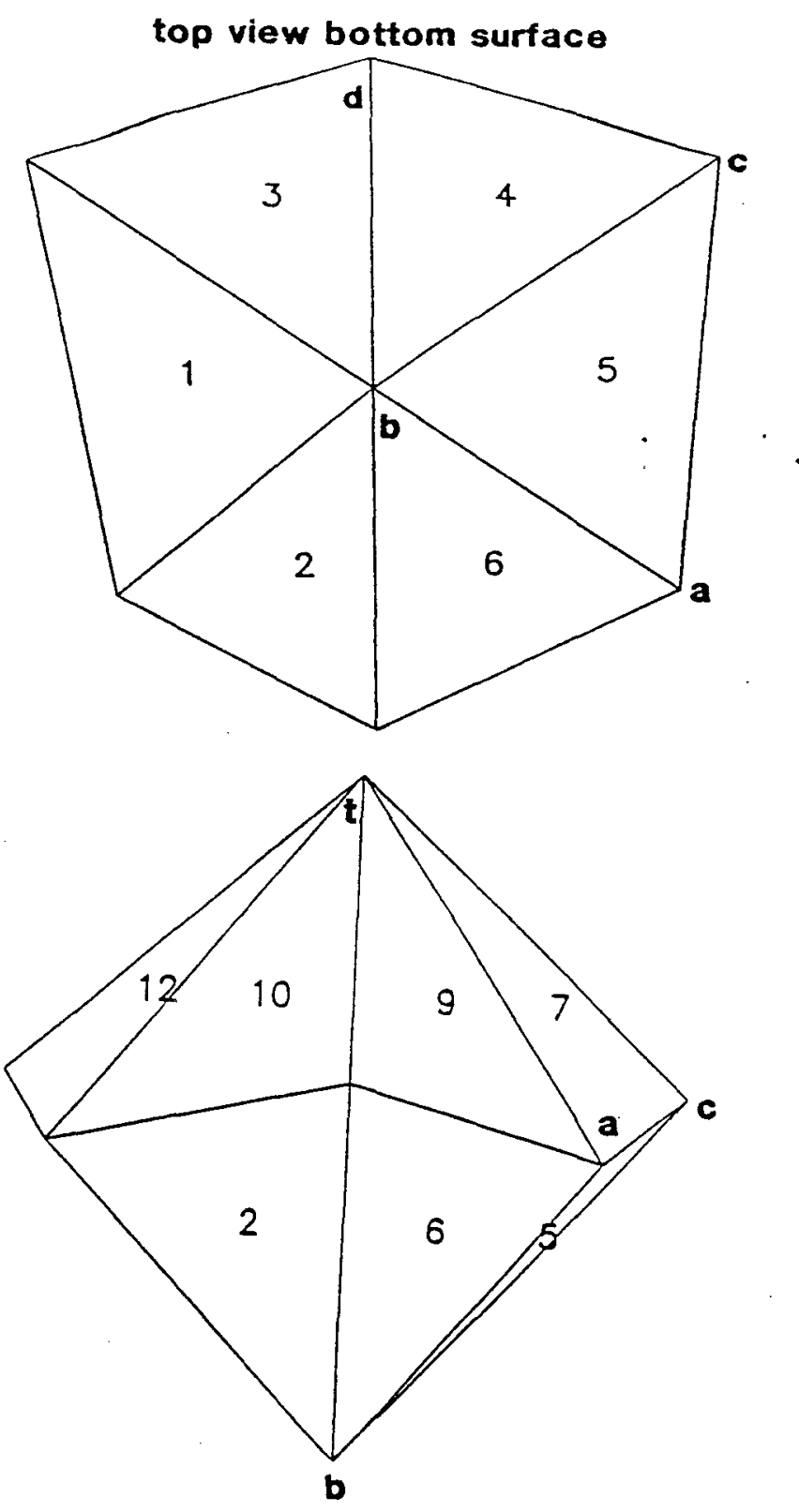

front view front surface

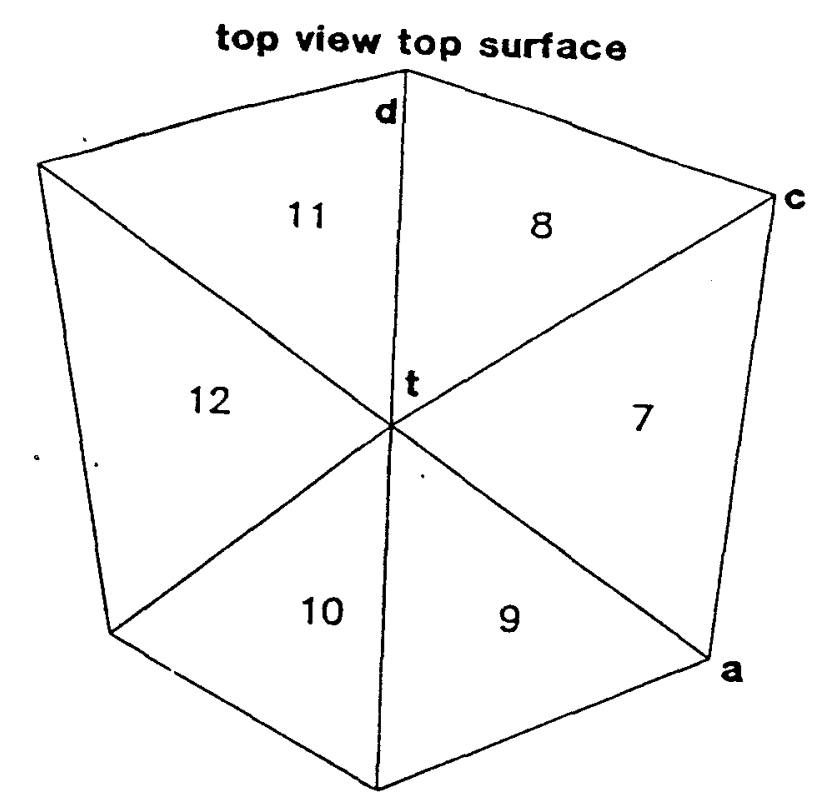

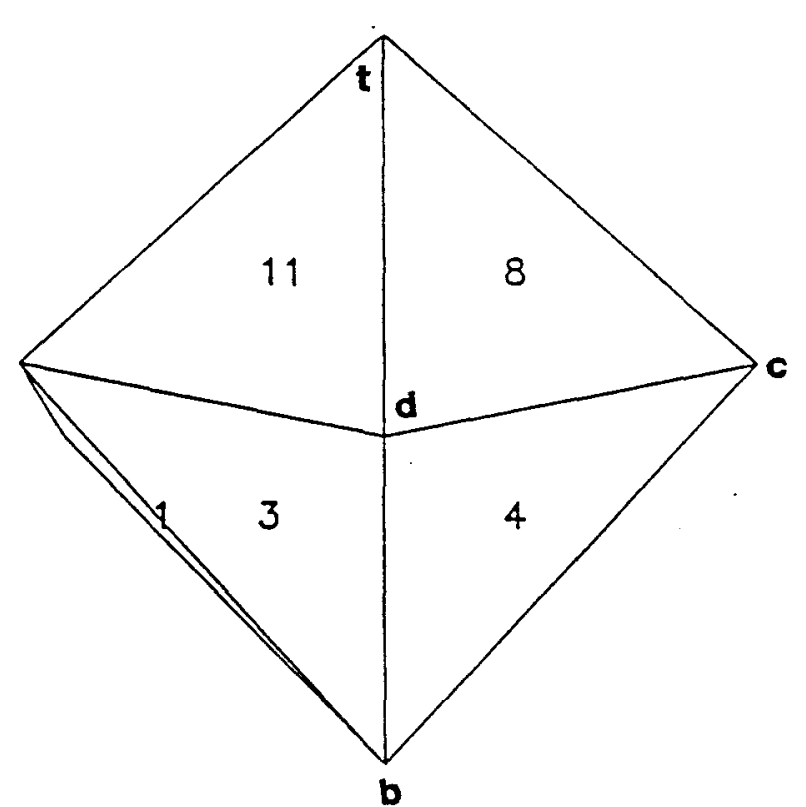

front view back surface

Figure 4. Determination of the minimum-volume polyhedral surface enclosing a set of points. This figure depicts front and top views of the front and back surfaces of a polyhedral surface enclosing 8 points and having 12 faces. Suppose we have already determined the six face triangles (labeled 1 to 6) connected to the bottommost point, labeled $b$. To find additional faces, consider the polygon formed by the upper edge of the 6 previously found faces. There are two ways to find additional faces. One way is to connect the lowermost point a on the hexagonal edge polygon to a point such as point $t$, and then add face 7 formed by points $t$, a, and $c$. This way adds a 7 th face and also increases the number of sides of the edge polygon from 6 to 7. The other way is to connect non-adjacent points on the edge polygon such as such as $t$ and $d$, forming face 8 from the points $\mathrm{c}, \mathrm{d}$, and $\mathrm{t}$. This adds an 8 th face but reduces the number of sides of the edge polygon from 7 to 6 . The bounding polyhedron is complete when the last face is found, reducing the number of sides of the edge polygon from three to two. 
The computational algorithm for determining the minimum volume convex polyhedron proceeds as follows:

Step 1. Read in three spatial coordinates for a set of $\mathrm{N}$ points in space, and place them in an array $R(3, N)$.

Step 2. Sort the array $\mathrm{R}$ in terms of its first coordinate; thus, points are rordered so that the first coordinate ranges from smallest to largest values, i. e., $R(1,1)<R(1,2)$ $<\mathrm{R}(1,3)<\ldots . \mathrm{R}(1, \mathrm{~N}-1)<\mathrm{R}(1, \mathrm{~N})$.

Step 3. Begin search to find the first face of the polyhedron: For computational purposes we will search the points beginning with the lowermost, as defined by the first coordinate (i.e., the points $\mathrm{R}(1, \mathrm{k})$ ). We begin the search by considering points between $\mathrm{k}=\mathrm{k}_{\text {low }}$ and $\mathrm{k}=\mathrm{k}_{\mathrm{high}}$, with $\mathrm{k}_{\text {low }}=1$ and $\mathrm{k}_{\mathrm{high}}=3$. At this time we have found no faces, so $\mathrm{n}_{\text {faces }}=0$.

Step 4. Loop over $k_{\text {mid }}$, where $k_{\text {mid }}$ is a number such that $k_{\text {low }}<k_{\text {mid }}<k_{\text {high }}$. Thus, search through planes determined by points $k_{l o w}, k_{\text {mid }}$, and $k_{h i g h}$. For each plane ( $k_{\text {low }}, \mathrm{k}_{\text {mid }}, \mathrm{k}_{\text {high }}$ ), check all $\mathrm{N}$ points to see if all lie within or on the same side of the plane. If so, proceed to Step 5. If not, increment $k_{\text {high }}$ by 1 and repeat Step 4.

Step 5. Now $n_{\text {faces }}=1$. Define the "edge polygon" as the triangle with $n_{\text {edgepoly }}=$ 3 points $\left(k_{\text {low }}, k_{\text {mid }}, k_{\text {last }}=k_{\text {high }}\right)$. Go to Step 6 .

Step 6. Loop over $\mathrm{k}$ for $\mathrm{k}>\mathrm{k}_{\mathrm{low}}$, searching through planes determined by points $\mathrm{k}_{\text {low }}, \mathrm{k}$, and $\mathrm{k}_{\text {last. }}$ For each plane ( $\mathrm{k}_{\text {low }}, \mathrm{k}, \mathrm{k}_{\text {last }}$ ), check all $\mathrm{N}$ points to see if all lie within or on the same side of the plane. When this occurs, proceed to Step 7.

Step 7. Increment $\mathrm{n}_{\mathrm{faces}}$ by 1 . Since we have just added a triangular face bounded on one side by points $k_{\text {low }}$ and $k_{l a s t}$ on the edge polygon, insert point $k$ as the $(n+1) s t$ edge point between point $k_{\text {low }}$ and $k_{\text {last }}$, and increment $n_{\text {edgepoly }}$ by 1 .

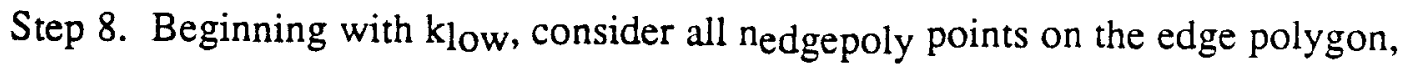
connecting each trio $\mathrm{k}_{\mathrm{i}}, \mathrm{k}_{\mathrm{j}}, \mathrm{k}_{\mathrm{m}}$ of adjacent points. Check to see if the plane formed by these three points is a face (with all $\mathrm{N}$ points in $\mathrm{S}$ within or on the same side of the plane). If so, increment $n_{\text {faces }}$ by 1 , remove point $k_{j}$ from the edge polygon, thus decrementing 
$\mathrm{n}_{\text {edgepoly }}$ by 1 . If $\mathrm{n}_{\text {edgepoly }}$ is now 2 , go to Step 10 . Repeat Step 8 till one has considered all trios of adjacent points on the edge polygon without finding a new face.

Step 9. Find the smallest of the $n_{\text {edgepoly }}$ numbers describing the edge polygon, and let this be $k_{\text {low }}$. Let $k_{\text {last }}$ be the number describing the lower of the two points adjacent to $k_{\text {low. }}$ Go to Step 6.

Step 10. The bounding polyhedron is now complete. With the addition of the last triangular face in Step 8, the number of points $n_{\text {edgepoly }}$ in the edge polygon went from 3 to 2. All $\mathrm{N}$ points either lie within or on the surface of the polyhedron formed by the faces, numbering $\mathrm{n}_{\text {faces. }}$.

In practice, certain bookkeeping procedures help to insure the robustness of the above procedure for determining the bounding polyhedron:

- When the algorithm is successful, each of the edges connecting adjacent extremities of the bounding polyhedron is attached to exactly two triangular faces. Thus, after determining the number of faces $n_{\text {faces }}$ making up the bounding polyhedron, we also find the number of points $n_{p o i n t s}$ and number of edges $n_{\text {edges }}$ at its extremities, and check to see that each edge has two faces in common.

- If more than three points in $\mathrm{S}$ lie in the plane determined by one of the faces, because of roundoff error the program may incorrectly determine that the fourth point is not within the bounding polyhedron. Thus, we normally consider that a point lies within the polyhedron if it lies in or within a specified distance, say 0.0001 units, of the surface.

- If the above type of numerical instability still prevents the program from finding the bounding polyhedron, we add a small normally distributed random component (a "jiggle" of perhaps 0.001 units) to each of the $\mathrm{N}$ points in $\mathrm{S}$, and then apply the algorithm again.

Statistics: Bounding Volume, Surface Area, Shape Factor: Because the bounding polyhedron is convex, we can determine its volume $\mathrm{V}$ by fixing some point in the interior and finding the the sum of volumes of tetrahedra formed by each face and the interior point. Two such interior points will simply be the points whose coordinates are the average of all the $\mathrm{N}$ points in $\mathrm{S}$, or the average of all the $\mathrm{n}_{\text {points }}$ points forming the exterior of the 
polyhiedron. The volume of each of the constituent tetrahedra will just be the area of the triangular face times one third of the perpendicular distance between the interior point and the plane containing the face.

Similarly, we can determine the surface area A of the bounding polyhedron by adding up the areas of each of the face triangles that make up the bounding polyhedron. From the volume $\mathrm{V}$, we can calculate an approximate linear dimension $\mathrm{V}^{1 / 3}$ for the group of events.

In addition, from $\mathrm{V}$ and the surface area $\mathrm{A}$ we can calculate a "shape factor" (Table 3). We define the shape factor to be $[\mathrm{V} /(4 \pi / 3)]^{1 / 3} /[\mathrm{A} / 4 \pi]^{1 / 2}$. This means that the shape factor approaches 1.0 as the shape of an object approaches the shape of a perfect sphere, it approaches 0.0 as the shape flattens out like a pancake or is drawn out like a a string, and it lies between 0.0 and 1.0 for all other shapes. Essentially, the shape factor measures the degree of sphericity of a shape. Calculating the the shape factor for a bounding polyhedron for a set of points allows us to determine whether the points occupy a volume in space, or alternatively, whether they occupy a flat or needle-shaped region.

If a group of events all lie at the same focal depth they will occupy zero volume, thus both $\mathrm{V}^{1 / 3}$ and the shape factor will be 0 . For example, for the relocation of Mururoa explosions we fixed the focal depths at $1.0 \mathrm{~km}$. Thus, to evaluate the compactness of the epicentral groups we calculated the surface area $A_{S}$ of the polygon containing the events, and determined the approximate spatial extent to be $A_{s} 1 / 2$.

\section{Test Data}

We utilize seismic data from three different geographic regions to evaluate how method of location affects the volumes of groups of hypocenters. These three regions are: 1.) the intermediate-focus "nest" of earthquakes occurring near Bucaramanga, Colombia; 2) nuclear explosions from Mururoa, in French Polynesia, and reported in the Bulletin of the International Seismological Centre (ISC); and 3) small earthquakes occurring in a nest of activity west of Efate, Vanuatu, and recorded by an ocean bottom seismograph experiment in 1989 (Olson, 1991).

Earthquakes in the Bucaramanga Nest: Near the town of Bucaramanga, Colombia, there exists a "nest" of earthquakes at a depth of approximately $160 \mathrm{~km}$ focal depth 
Table 3: Shape Factors for some Familiarly Shaped Objects.

If $\mathrm{V}$ and $\mathrm{A}$ are the volume and surface area of an object, then the shape factor is defined to be $(\mathrm{V} / 3 \pi)^{1 / 3} /(\mathrm{A} / 4 \pi)^{1 / 2}$

Object

1. Sphere, radius $\mathbf{R}$

2. Cube, side $\mathrm{S}$

3. Rectangular Solid, sides $\ell, \mathrm{w}, \mathrm{d}$

3a. Example $w=1, d=1, \ell=4$

3b. Example $w=10, d=10, \ell=1$

4. Pyramid with square base of side $\mathrm{S}$, height $\mathrm{h}$
Surface Area

$4 \pi R^{2}$

$6 S^{2}$

$2(\ell w+w d+\ell d)$

18

240

100

$\frac{1}{3} S^{2} h$

$$
s^{2}\left(1+\sqrt{1+\left(\frac{2 h}{s}\right)^{2}}\right)
$$$$
\frac{1.52\left(\mathrm{~S}^{2} \mathrm{~h}\right)^{1 / 3}}{\left(1+\sqrt{1+\left(\frac{2 h}{\mathrm{~S}}\right)^{2}}\right)^{1 / 2}}
$$

0.82

4a. Example $\mathrm{S}=\mathrm{h}=1$

$$
\frac{1}{3}
$$

$1+\sqrt{5}$

4b. Example $S=10, h=1$

$\frac{100}{3}$

202

4c. Example $S=1, h=10$

0.84

0.50

$$
\frac{1.55(\ell w d)^{1 / 3}}{(\ell w+w d+\ell d)^{1 / 2}}
$$

0.65

0.72 
(Schneider et al., 1987). The ISC reports about 217 events having magnitudes of 4.7 or greater occurring between 1964 and 1992. Of these, we chose 41 occurring between 1964 and 1977 for which we had ISC phase information, and which were observed at 100 or more stations, occurred between $6.7^{\circ} \mathrm{N}$ and $6.9^{\circ} \mathrm{N}$, between $72.9^{\circ} \mathrm{W}$ and $73.1^{\circ} \mathrm{W}$, and had focal depths between $140 \mathrm{~km}$ and $180 \mathrm{~km}$ (Figure 5). For the relocation, we utilized stations which recorded $\mathrm{P}$ or $\mathrm{PKP}$ phases for at least half of the above events. These were: local stations (BCR, BMG, CHN, and PSO), regional stations (ARE, BAO, BDF, BOG, BOCO, CAR, HRA, LPB, NNA, PNS, TRN, SDV, TOV, ZLP, and ZOBO), North American stations and arrays (ALQ, BMO, CPO, EUR, GOL, MBC, SCH, UBO and YKA), and various distant stations (CHG, EKA, GBA, KIC, KOD, SHL, SPA and WRA). All of the phase data used were reported by the ISC, i. e., none of the phases were personally read by the author.

For the remainder of this report we shall refer to this group of earthquakes as data set B-1. The principal properties which characterize data set B-1 are intermediate focal depth, teleseismic phase data, and good azimuthal control.

We compare these locations to several different sets of reported locations from the Bucaramanga region. Dewey (1972) carefully evaluated arrivals for Bucaramanga events occurring between 1958 and 1970 and reported in the ISC bulletins, and personally reread selected phase observations. From these data he assigned 93 events a quality rating of "A"- these events comprise data set B-2. The Harvard group has reported centroid moment tensors (CMT) for 14 events occurring between 1977 and 1992, and the locations of these events are data set B-3. Using observations from a temporary network of local stations (3 weeks in 1979), Schneider et al. (1987) precisely determined 27 hypocenters in the Bucaramanga nest. We did not relocate these events as Schneider et al. (1987) did not report phase information. However, these 27 earthquakes represent Schneider's "best" events, and are thought to be representive of the location and spatial extent of the nest. We shall call these events data set B-4.

Nuclear Explosions from Mururoa Recorded Teleseismically: Between 1977 and 1988 about 55 nuclear explosions have occurred in Mururoa which are large enough to be recorded teleseismically and located by the ISC. From these events, we have selected 29 events (Figure 6) which possessed phase data at a majority of the following stations: ALQ, BDW, EUR-BMN, BNG, COL, CTA, DOU, EDM, FVM, GBA, GLA, GOL, JAS, KDC, DJF, LJU, LBP-ZOBO, FRI-MHC-PRI, MOA, NDI, NEW-PNT, NIE, NUR, 


\subsection{W}

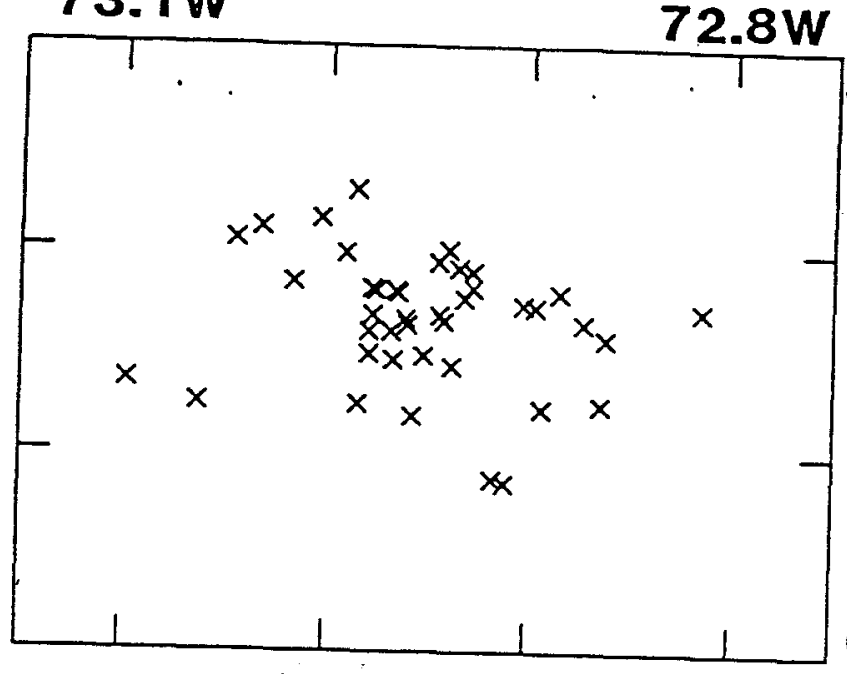

\section{Bucaramanga}

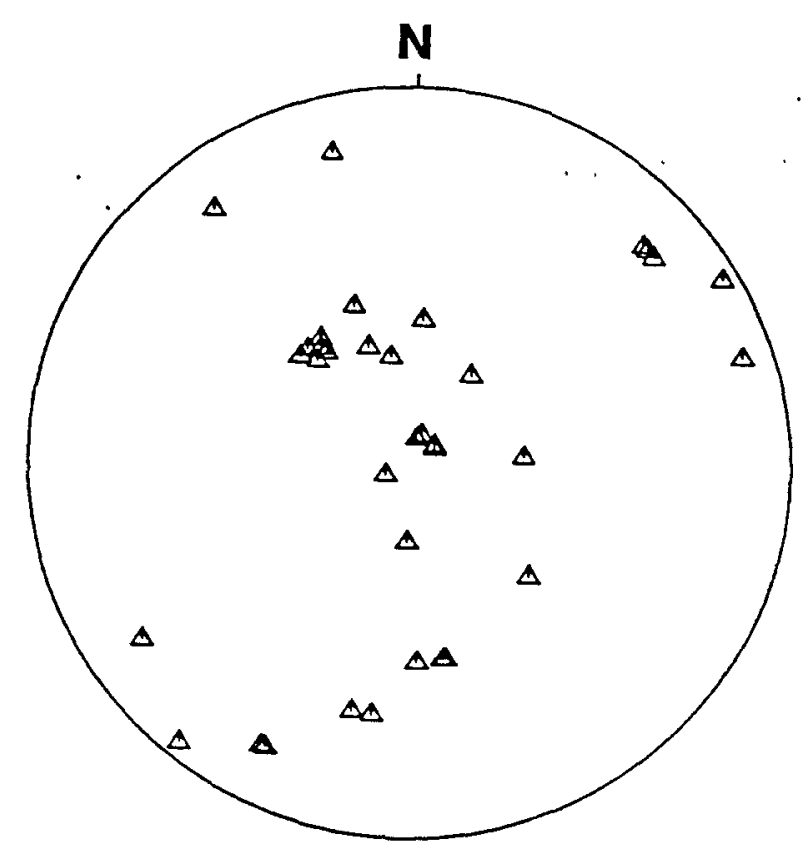

Figure 5 The map on the left shows the JHD relocations for the 41 earthquakes (X's) in data set B-1, near Bucaramanga, Colombia. The diagram on the right is a stereographic projection showing the azimuthal distribution of stations (triangles) used for the relocation of these events. Note that there is a reasonably good azimuthal distribution of stations for both distant and nearby stations. 

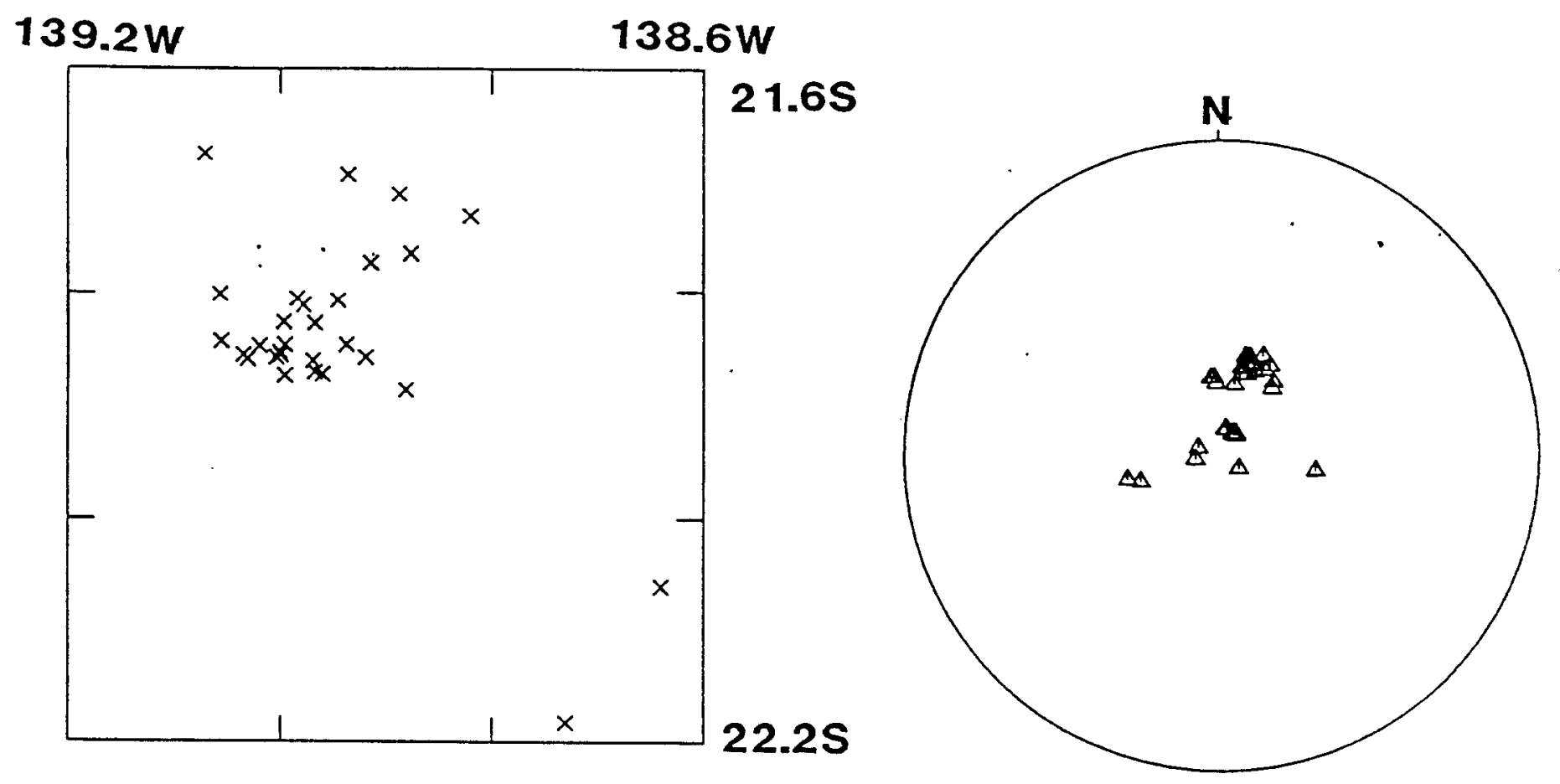

\section{Mururoa}

Figure 6 The map on the left shows the locations reported by ISC for the 29 nuclear explosions (X's) in data set T-1, near the Mururoa, French Polynesia. The diagram on the right is a stereographic projection showing the azimuthal distribution of stations (triangles) used for the relocation of these events. Note that because there are no nearby stations all the stations lie near the center of the focal sphere, and most lie to the north and northeast of the source region. 
PMR, BRG-GRF-KGC-PRA-PRU, SES, TUL, WRA, YKA-YKC, WDC, and ZST (for $\mathrm{JHD}$ relocation we determined a single common station correctionstation groups connected by a "-"). These stations were selected because they reported P or PKP arrivals for more than $50 \%$ of the events. Generally, the available phase data are limited mostly to two azimuths, one from stations primarily in North America, and the other from a few stations in Australia. Many of the best available phase data come from PKP phases. In all our relocations we have fixed the focal depths of these events at $1.0 \mathrm{~km}$.

These events form data set $\mathrm{T}-1$. The principal properties which characterize the set $\mathrm{T}-1$ are shallow focal depth, teleseismic phase data, and poor azimuthal control.

\section{Earthquakes Recorded by Ocean Bottom Seismographs in Vanuatu:}

Just west of the island of Efate in Vanuatu (formerly, the New Hebrides) there exists a distinct concentration of shallow earthquake activity (Chatelain et al., 1986). Neither teleseismic locations nor locations from the Vanuatu land network adequately constrain the geometry of these locations. In 1989, the University of Texas at Austin and the French agency ORSTOM jointly operated two networks (Olson et al., 1991) of approximately 10 ocean bottom seismographs (OBS, described in Frohlich et al., 1990) to augment the land network and study these events. From the earthquakes located by the joint OBS-land network, we have selected 46 events (Figure 7). Each of these events was situated between $17.35^{\circ} \mathrm{S}$ and $17.85^{\circ} \mathrm{S}, 167.7^{\circ} \mathrm{E}$ and $168.2^{\circ} \mathrm{E}$, with focal depths between 20 $\mathrm{km}$ and $45 \mathrm{~km}$, and was located using $P$ phases from 5 or more stations, $S$ phases from 3 or more stations, and an azimuthal gap of 240 degrees or less.

The 46 events which meet these three criteria form the data set $V-1$. The principal properties which characterize the set $\mathrm{V}-1$ are shallow focal depth, local network phase data, and good azimuthal control. Data set V-2 is a subset of the events in V-1, chosen to have an azimuthal gap of 180 degrees or less. Of these 22 events, data set $\mathrm{V}-2 \mathrm{~A}$ are 10 events recorded during the first OBS deployment from 22 June to $16 \mathrm{July,} 1989$, and data set V2B are 12 events recorded during the second OBS deployment from 21 July to 19 August, 1989. 


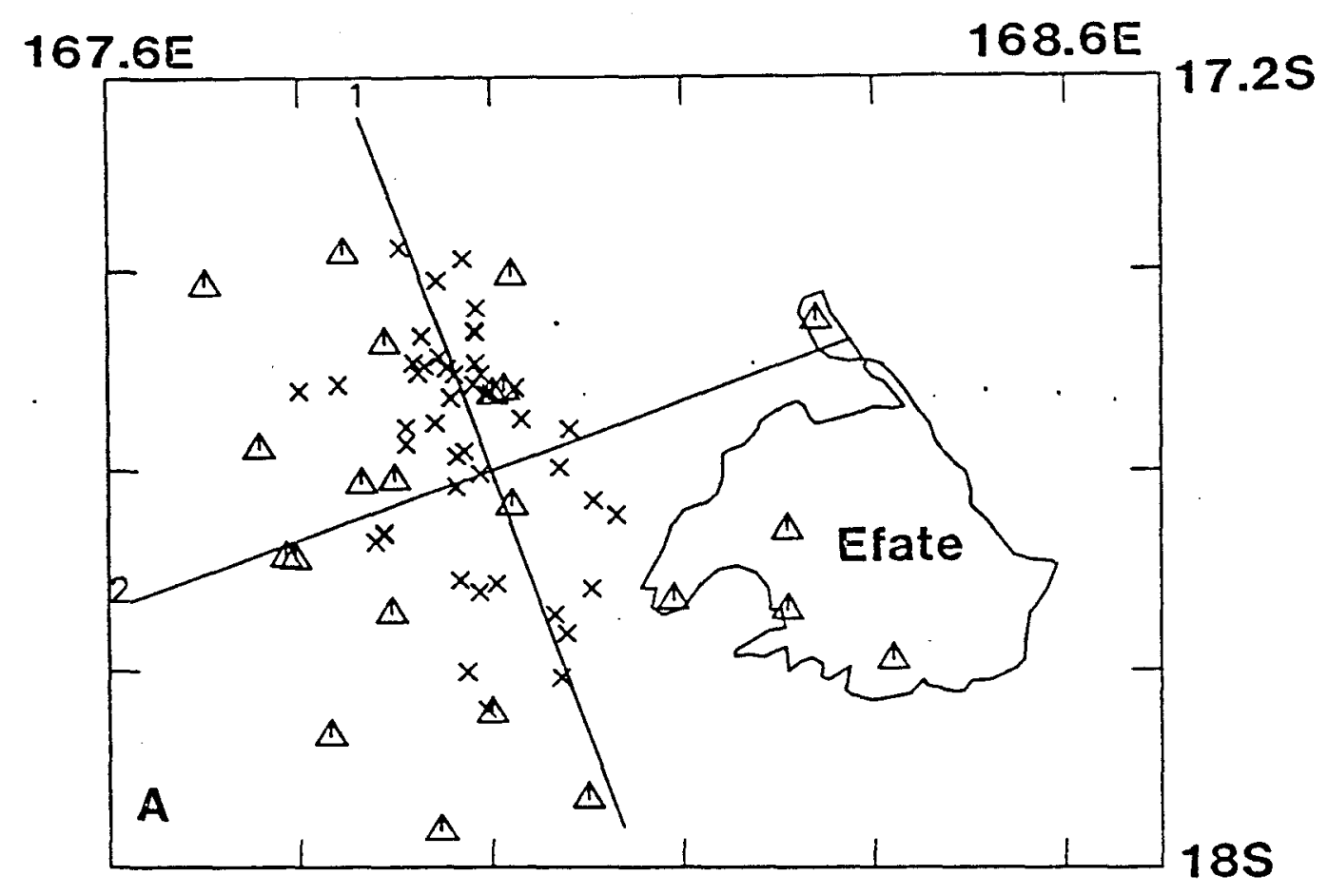

2
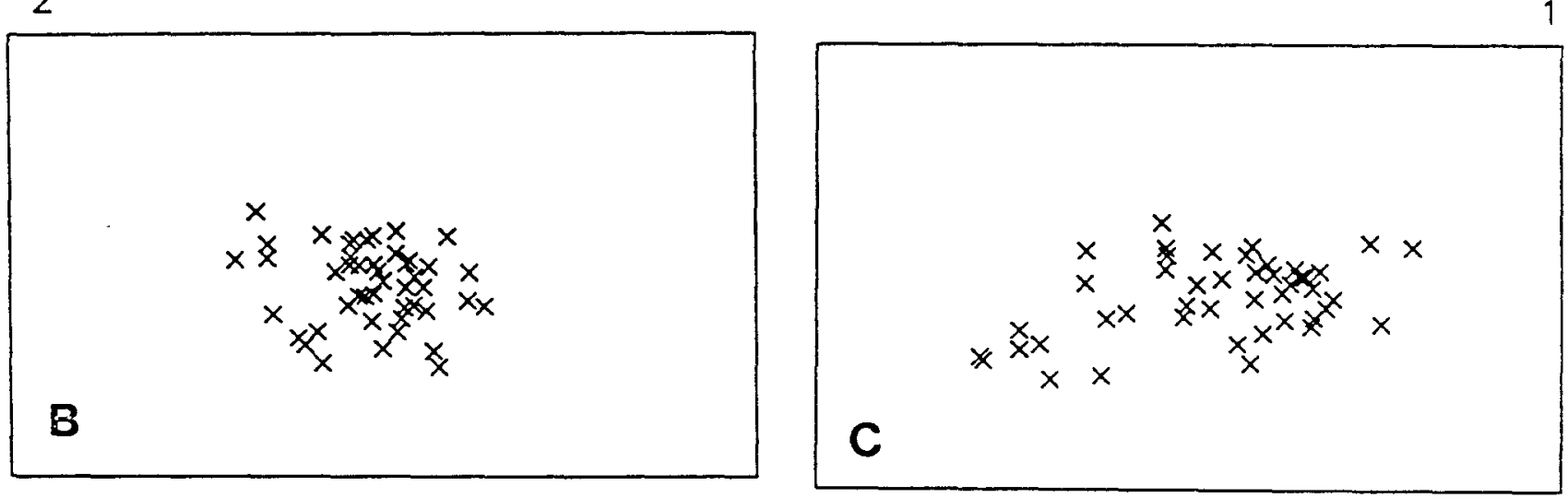

Figure 7. The map A shows the locations of 15 OBS stations (triangles), 5 land stations (triangles), and 46 earthquake events (X's) in data set V-1, near Efate, Vanuatu. The locations shown are determined by the single-event method. Cross sections $B$ and $C$ are at the same scale as the map, and are oriented as shown by the crossed lines on the map. 


\section{RESULTS}

\section{A. Earthquakes in the Bucaramanga Nest:}

The calculated volume of the Bucaramanga nest differs considerably for the various data sets (Table 4). For data set B-1 it also varies depending on the method of relocation. The calculated volumes ranged from $25,526 \mathrm{~km}^{3}$ for set $\mathrm{B}-3$, the Harvard CMT data, to $11.2 \mathrm{~km}^{3}$ for set B-4, the local network locations of Schneider et al. (1987). However, the Harvard data represent 15 years of seismic observations, whereas the Schneider et al. (1987) observations represent data collected only over a 3 week period. If we approximate the spatial extent of the nest as the cube root of the calculated volume $\mathrm{V}$, then these extreme results correspond to spatial extents ranging from 2.2 to $29.4 \mathrm{~km}$. Dewey's (1972) selected and relocated events, data set B-2, has a spatial extent of $18.4 \mathrm{~km}$, significantly larger than the $13.7 \mathrm{~km}$ for set $\mathrm{B}-1$, the reported ISC locations.

For data $\mathrm{B}-1$, our single event relocations using about 30 selected stations possess a considerably larger volume $\left(12,389 \mathrm{~km}^{3}\right.$ or a spatial extent of $\left.23.1 \mathrm{~km}\right)$ than the volume from the original ISC reported locations $\left(2,591 \mathrm{~km}^{3}\right.$, or a spatial extent of $\left.13.7 \mathrm{~km}\right)$, determined using 100 stations or more. However, the set becomes considerably more compact when we undertake $\mathrm{JHD}$ relocations using the same observations-- the volume for the 41 events becomes $2,087 \mathrm{~km}^{3}$ or a spatial extent of $12.8 \mathrm{~km}$. This is virtually identical to the volume and spatial extent of the original ISC locations. However, as expected the JHD relocation does bring about an approximately $60 \%$ reduction in the RMS residual of the phase arrivals, from $1.42 \mathrm{sec}$ to $0.64 \mathrm{sec}$.

We can make some crude estimates of rates of strain release within the source region of the Bucaramanga nest by making some assumptions about the relationship between magnitude, moment, and strain. As noted by Kostrov (1974), the tensor relationship between seismic moment release $\mathbf{M}$ and strain $\varepsilon$ associated with seismic activity is

$$
\varepsilon=\frac{M}{2 \mu \mathrm{V}}
$$

where $\mathrm{V}$ is the volume of the region radiating seismic moment, and $\mu$ is ridigity (see also Frohlich and Apperson, 1992). We can use the moment reported by the Harvard CMT to calculate the moment release rate within the Bucaramanga nest since 1977. For activity prior to 1977 we can estimate the moment release using the approximate relationship 


\begin{tabular}{|c|c|c|c|c|c|c|}
\hline Data Set & $\begin{array}{l}\text { Number } \\
\text { of Events }\end{array}$ & Location by... & $\mathrm{RMS}(\mathrm{sec})$ & Volume $\left(\mathrm{km}^{3}\right)$ & Volume $^{1 / 3}(\mathrm{~km})$ & Shape Factor \\
\hline \multicolumn{7}{|c|}{ Bucaramanga Earthquakes - Reported Locations } \\
\hline B-1 & 41 & ISC & $-\cdots-$ & 2,591 & 13.7 & 0.903 \\
\hline B-2 & 93 & Dewey (1972) & ---- & 6,199 & 18.4 & 0.871 \\
\hline B-3 & 14 & Harvard CMT & $-\cdots-$ & 25,526 & 29.4 & 0.770 \\
\hline $\mathrm{B}-4$ & 27 & Schneider et al. (1987) & $\cdots+$ & 11.2 & 2.2 & 0.828 \\
\hline \multicolumn{7}{|c|}{ Bucaramanga Earthquakes - Relocations (this study) } \\
\hline B-1 & 41 & Single Event - wts $\mathrm{G}$ & 1.42 & 12,389 & 23.1 & 0.878 \\
\hline $\mathrm{B}-1$ & 41 & JHD - wts G & 0.64 & 2,087 & 12.8 & 0.815 \\
\hline \multirow[t]{2}{*}{ Data Set } & $\begin{array}{l}\text { Number } \\
\text { of Events }\end{array}$ & Location by... & RMS (sec) & Area $\left(\mathrm{km}^{2}\right)$ & Area $^{1 / 2}(\mathrm{~km})$ & Shape Factor \\
\hline & \multicolumn{5}{|c|}{ Tuamoto Explosions - Reported Locations } & $\therefore$ \\
\hline \multirow[t]{2}{*}{$\mathrm{T}-1$} & 29 & ISC & $-\cdots$ & 1,406 & 37.4 & 0 \\
\hline & \multicolumn{5}{|c|}{ Tuamoto Explosions - Relocations (this study) } & $\cdot$ \\
\hline $\mathrm{T}-1$ & 29 & Single Event - no wts & 2.77 & 10,762 & 103.7 & 0. \\
\hline $\mathrm{T}-1$ & 29 & Single Event - wts G & 2.21 & 23,078 . & 151.9 & 0. \\
\hline $\mathrm{T}-1$ & 29 & JHD - no wts & 1.36 & 3,548 & 59.6 & 0. \\
\hline $\mathrm{T}-1$ & 29 & JHD - wts G, A & 0.91 & 2,135 & 46.2 & 0 \\
\hline Data Set & $\begin{array}{c}\text { Number } \\
\text { of Events }\end{array}$ & Location by... & $\mathrm{RMS}(\mathrm{sec})$ & Volume $\left(\mathrm{km}^{3}\right)$ & Volume $^{1 / 3}(\mathrm{~km})$ & Shape Factor \\
\hline \multicolumn{7}{|c|}{ Vanuatu Earthquakes - Relocations (this study) } \\
\hline $\mathrm{V}-1$ & 46 & Single Event & 0.39 & 7,789 & 19.8 & 0.902 \\
\hline V-1 & 46 & JHD & 0.29 & 14,259 & 24.2 & 0.796 \\
\hline$V-2$ & 22 & Single Event & 0.41 & 5,276 & 17.4 & 0.778 \\
\hline $\mathrm{V}-2$ & 22 & JHD & 0.24 & 6,787 & 18.9 & 0.772 \\
\hline$V-2 A$ & 10 & $\mathrm{SE}$ & 0.37 & 2,072 & 12.7 & 0.775 \\
\hline$V-2 A$ & 10 & JFID & 0.22 & 2,015 & 12.6 & 0.771 \\
\hline$V-2 B$ & 12 & $\mathrm{SE}$ & 0.42 & 682 & 8.8 & 0.618 \\
\hline$V-2 B$ & 12 & $\mathrm{MHD}$ & 0.24 & 1,447 & 11.3 & 0.678 \\
\hline
\end{tabular}




$$
M_{o}=10^{\frac{3}{2}\left(M_{w}+10.7\right)}
$$

where $M_{W}$ is the magnitude and $M_{O}$ is the seismic moment (Hanks and Kanamori, 1979).

. The moment release rate calculated in this way is approximately $5-10 \times 10^{16}$ dyne$\mathrm{cm} / \mathrm{sec}$ whether calculated from Harvard or ISC data, or from earthquakes occurring before or after 1977 (Table 5). We can estimate the strain rate if the volume of the nest is in the range $10-2000 \mathrm{~km}^{3}$, as estimated in Tables 4 and 5 , and if $\mu$ is about $1.2 \times 10^{11}$ Pascals, as estimated by Dziewonski et al. (1975) for the mantle at a depth of about $200 \mathrm{~km}$. This calculation finds that the strain rate within the Bucaramanga nest lies between $10^{-14} / \mathrm{sec}$ and $4 \times 10^{-12} / \mathrm{sec}$ (Table 5).

\section{B. Nuclear Explosions from Mururoa Recorded Teleseismically:}

Relocation of the the Mumuroa events in data set $\mathrm{T}-1$ does not bring the epicenters into a more compact group, indeed, the epicenters reported by the ISC fit in a smaller polygonal area $\left(1,406 \mathrm{~km}^{2}\right)$ than do any of the relocated epicenter groups (Table 4). The only relocation method to produce a group with a comparable compactness was when we applied JHD using both Gaussian weighting and azimuthal weighting of residuals ("JHD wts $G, A^{\prime \prime}$ in Table 4).

However, the application of $\mathrm{JHD}$ and various weighting schemes did reduce the RMS residuals as expected. Both JHD relocations had RMS residuals about half of the size those from the single event relocations ( 0.91 and $1.36 \mathrm{sec}$, compared to 2.21 and 2.77 $\mathrm{sec}$ ). Also, for both JHD and single event relocations the application of Gaussian weighting reduced the RMS residuals by about $0.5 \mathrm{sec}$.

\section{Earthquakes Recorded by Ocean Bottom Seismographs in Vanuatu:}

For data sets $\mathrm{V}-1, \mathrm{~V}-2$, and $\mathrm{V}-2 \mathrm{~A}$ relocation using JHD actually produced a less compact group of hypocenters than did single-event relocation (Table 4). For example, for $\mathrm{V}-1$ the volume was $7,789 \mathrm{~km}^{3}$ for single-event relocation, and $14,259 \mathrm{~km}^{3}$ for JHD relocation. For data set $\mathrm{V}-1$, this may occur because about half of these events have azimuthal gaps exceeding $180^{\circ}$. Also, sets $\mathrm{V}-1$ and $\mathrm{V}-2$ contain events from two different OBS deployments, although during both deployments the events recorded by OBS were 
Table 5: Moment Sums and Strain Rates for the Bucaramanga Nest

\begin{tabular}{lccccc}
\hline Data Source & Years & $\begin{array}{c}\text { Number } \\
\text { Earthquakes }\end{array}$ & $\begin{array}{c}\text { Moment Rate } \\
(\text { dyne-cm/sec })\end{array}$ & $\begin{array}{c}\text { Minimum Strain Rate* } \\
\left(\mathrm{sec}^{-1}\right)\end{array}$ & $\begin{array}{c}\text { Maximum Strain Rate** } \\
\left(\mathrm{sec}^{-1}\right)\end{array}$ \\
\hline ISC & $1964-1992$ & 200 & $8.14 \times 10^{16}$ & $1.69 \times 10^{-14}$ & $3.39 \times 10^{-12}$ \\
ISC & $1964-1976$ & 89 & $10.04 \times 10^{16}$ & $2.09 \times 10^{-14}$ & $4.18 \times 10^{-12}$ \\
ISC & $1977-1992$ & 111 & $6.90 \times 10^{16}$ & $1.27 \times 10^{-14}$ & $2.54 \times 10^{-12}$ \\
Harvard CMT & $1977-1992$ & 14 & $4.74 \times 10^{16}$ & $0.99 \times 10^{-14}$ & $1.98 \times 10^{-12}$ \\
\hline
\end{tabular}

*Minimum strain rate assumes a volume of $2000 \mathrm{~km}^{3}$ and a rigidity of $1.2 \times 10^{11}$ Pascals

${ }^{* *}$ Maximum strain rate assumes a volume of $10 \mathrm{~km}^{3}$ and a rigidity of $1.2 \times 10^{11}$ Pascals 
- also observed on common land stations. When we separate data from each OBS deployment to form sets $\mathrm{V}-2 \mathrm{~A}$ and $\mathrm{V}-2 \mathrm{~B}$, the $\mathrm{JHD}$ relocations for $\mathrm{V}-2 \mathrm{~B}$ are still less compact than the single event relocations.

For all the Vanuatu data sets, the spatial extent $\left(\mathrm{V}^{-1 / 3}\right)$ of the events was $25 \mathrm{~km}$ or less. In all cases the JHD relocations possessed RMS residuals about $25 \%-40 \%$ smaller than the single event relocations.

\section{DISCUSSION AND CONCLUSIONS}

For most seismic events, one never actually determines a "true" location, rather, we must obtain the most plausible locations possible using sparse, error-prone phase observations and a variety of location methods. Usually, before selecting a "best" location one prefers to locate the events using a variety of different methods and assumptions, and selecting different subsets of the data. To simply this process we are developing an especially flexible relocation program. The choice of various options is quite seamless; single event or JHD relocation; flat-earth or IASPEI91 travel times; unweighted, weighted, or azimuthally weighted residuals; individual or grouped station correction variables; etc.

In this report we utilize a preliminary version of this program to evaluate available data for three groups of seismic events; earthquakes in the intermediate focus "nest" near Bucaramanga, Colombia; nuclear explosions occurring in Mururoa; and small earthquakes occurring in a highly active area near Efate, Vanuatu, recorded by a network of land and temporary OBS stations. While these event groups are all similar in that the events occur within a very localized cluster, the groups are quite different otherwise, such as focal depth, local or teleseismic data (Table 1).

To evaluate how different relocation methods affect locations in these data clusters, we have developed a method for determining the smallest convex polyhedron which encloses a set of hypocenters. This is useful for evaluating locations when there are reasons to expect that several events all arise from the same focus or from a very localized region. As a seismological tool, plots of the polyhedron are useful for determining a gross shape for a group of epicenters. Also, the polyhedron is useful because it provides a method for assigning a unique volume and surface area to a group of epicenters. Most of the other methods we apply to these data are familiar to practicing seismologists, and do not require discussion here. 
When one desires to find locations for a localized group of hypocenters, it is instructive to compare the volume of the bounding polyhedron for the group as it is relocated by various methods. Often, there are reasons to expect that "better" locations will occupy a smaller volume, thus, the polyhedron volume represents a simple and quantitative way for choosing among various relocation methods. Seismologists often use the RMS residual as a statistic for evaluating location quality. However, for comparing different methods this is often misleading since location methods such as Gaussian weighting essentially ignores travel times which don't fit as expected, or ascribe it to a different origin. Similarly, JHD simply ascribes misfit to a different origin. Thus, the volume of a hypocentral group is in some ways superior as a method for making comparative evaluations of location methods.

The results of these comparisons are sometimes unexpected, for example, in some situations $\mathrm{JHD}$ relocations may actually be worse than single-event relocations. In this study this seems to have occurred for the relocations of events in Vanuatu (Table 4). Similarly residual weighting schemes designed to selectively ignore "inconsistent" data with large residuals may occasionally ignore the wrong data. This seems to have occurred for the single-event relocation of the Mururoa events.

While this study has concentrated on improving methods for finding and evaluating locations, it is always important to remember that improved location methods are no substitute for more and better data. Our relocations for the explosions in the Mururoa group provide a graphic illustration of the paradoxes that occur when data are sufficiently sparse or data quality is poor. For Mururoa, where there were no local phase observations, poor azimuthal control, little or no data redundancy in all but one azimuth, and no carefully reread phases, using an azimuthal Gaussian weighting scheme actually seemed to decrease the resolution of single event relocation.

This paradoxical situation apparently occurs because for Mururoa events there are phase observations from only one or two stations in all azimuths except for the azimuth with North American stations. Thus, in the sparse azimuths the azimuthal Gaussian weights sometimes caused the relocation program to undervalue "correct" phase arrival times and place undue confidence in "bad" data. Presently the locations reported by the ISC are more compact than our relocations simply because the ISC uses phase arrivals from all available stations to determine locations, thus, the additional redundancy gained by 
using all the data makes up for what is lost because the station network may be considerably different for various events. It would be instructive to compare our relocations using phase information reported by the ISC to relocations using only four to six stations, carefully selected to have a reasonable azimuthal coverage, and using $\mathrm{P}$ or PKP phases carefully reread by the author. The author's experience suggests that these relocations would be superior to any of those undertaken at present.

Of the data sets considered here, the Bucaramanga events were most localized in space, and the Bucaramanga data possessed the best azimuthal distribution of stations. For the Bucaramanga nest, there is no apparent improvement in location when we relocate events with a single-event method using selected stations and phase information reported by the ISC. However, if we apply JHD methods to the same data, we obtain a significantly more compact source volume, comparable to but slightly smaller than the source volume obtained by the ISC using all reported data.

It is interesting to speculate how localized the Bucaramanga hypocenters would become if we possessed phase arrival times that had been personally reread and checked to remove errors, etc. Dewey's (1972) data set B-2 represents a partial attempt to do this. Surprisingly, the bounding polyhdedron for the data set B-2 is even less compact than that for the ISC data (set B-1). If we had teleseismic phase observations of $\mathrm{P}, \mathrm{pP}$, and PKP read from broadband digitial stations would we find a Bucaramanga nest with the compactness observed from local data by Schneider et al. (1987)? Or is the nest really significantly larger than observed by Schneider et al. (1972), and only a portion of it was active during their study?

To our knowledge, this study is the first study to use earthquake moments to estimate the rate of seismic strain release within the Bucaramanga nest. The rates so determined are large. If we assume that the spatial extent of the nest is represented approximately by Schneider et al.'s (1972) hypocenters, then we obtain the strain rates of about $10^{-12} / \mathrm{sec}$ (Table 5), or, between $10^{-5} / \mathrm{yr}$ and $10^{-4} / \mathrm{yr}$. The strains accumulated in one year are approximately comparable to the strains measured in laboratory samples at failure, and thus it is unsurprising that the Bucaramanga nests generates earthquakes with such regularity. 


\section{REFERENCES}

Boyd, T.M. and J.A. Snoke, Error Estimates in Some Commonly used Location Programs, Earthquake Notes, 55, 3-6, 1984.

Carlson, W.D. and C. Denison, Mechanisms of Porphyroblast Crystallization: Results from High-Resolution Computed X-ray Tomography, Science, 257, 1236-1239, 1992.

Chatelain, J.-L. et al., Patterns of Seismicity Associated with Asperities in the Central New Hebrides Island Arc, J. Geophys. Res., 91, 12497-12519, 1986:

Dewey, J.W., Seismicity and Tectonics of Western Venezuela, Bull. Seism. Soc. Am., 62, 1711-1751, 1972.

Douglas, A., Joint Epicentre Determination, Nature, 215, 47-48, 1967

Dziewonski, A.M., A.L. Hales and E.R. Lapwood, Parametrically Simple Earth Models Consistent with Geophysical Data, Phys. Earth Plan. Int., 10., 12, 1975.

Flinn, E.A., Confidence Regions and Error Determination for Seismic Event Location, Rev. Geophys, 3, 157-185, 1965.

Frohlich C., An Efficient Method for Joint Hypocenter Deternination for Large Groups of Earthquakes, Comput. Geosci., 5, 387-389, 1979.

Frohlich C. et al, Detection and Location of Earthquakes in the Central Aleutian Subduction Zone Using Land and Ocean Bottom Seismograph Stations, J. Geophys. Res, 87, 6853-6864, 1982.

Frohlich C. and K.D. Apperson, Earthquake Focal Mechanisms, Moment Tensors, and the Consistency of Seismic Activity Near Plate Boundaries, Tectonics, 11, 279-296, 1992.

Frohlich, C. et al., Earthquake Activity in the Southern Vanuatu Arc Recorded by the Texas Digital OBS, Mar. Geophys. Res. 12, 253-267, 1990.

Hanks, T.C. and H. Kanamori, A Moment Magnitude Scale, J. Geophys. Res., 84, 23482350, 1979.

Hermann, R.B. et al., The Denver Earthquakes of 1967-68, Bull. Seism. Soc. Am., 71 , 731-745, 1981.

Jordan, T.H. and K.A. Sverdrup, Teleseismic Location Techniques and Their Application to Earthquake Clusters in the South-Central Pacific, Bull. Seism. Soc. Am., 71, 11051130, 1981.

Kennett, B.L.N. (ed.), IASPEI 1991 Seismological Tables, Research School of Earth Sciences, Australian National University, 1991.

Kostrov, V.V., Seismic Moment and Energy of Earthquakes, and Seismic Flow of Rock, Izv. Acad. Sci. USSR Phys. Solid Earth, Engl. Transl., 1, 23-44, 1974. 
McLaren, J.P. and C. Frohlich, Model Calculations of Regional Network Locations for Earthquakes in Subduction Zones, Bull. Seism. Soc. Am., 75, 397-413, 1985.

Olson, D.R. et al., Earthquake Locations from OBS and Local Network Records Near Efate, New Hebrides Trench, Vanuatu, EOS, 72, 348, 1991.

Pavlis, G.L., Appraising Relative Earthquake Location Errors, Bull Seism. Soc. Am., 82, 836-859, 1992.

Pavlis, G.L. and J.R. Booker, Progressive Multiple Even Location (PMEL), Bull. Seism. Soc. Am., 73, 1753-1777, 1983.

Pavlis, G.L. and N.B. Hokanson, Separated Earthquake Location, J. Geophys. Res., 90, 12777-12789, 1985.

Pujol, J., Comments on the Joint Determination of Hypocenters and Station Corrections, Bull. Seism. Soc. Am., 78, 1179-1189, 1988.

Schneider, J.F. et al., Microseismicity and Focal Mechanisms of the Intermediate-Depth Bucaramanga Nest, Colombia, J. Geophys. Res., 92, 13913-13926, 1987.

Tichelaar, B.W. and L.J. Ruff, How Good are Our Best Models?, EOS, 20, 605-606, 1989.

Willemann, R.J. and C. Frohlich, Spatial Patterns of Aftershocks of Deep Earthquakes, $J$. Geophys. Res, 92, 13927-13943, 1987. 